This is a postprint version of the following published document:

Peinado, C., Catalina, F. \& Miguel, V. S. (2007): Synthesis and association properties in water solution of random copolymers of 2-acrylamido-2-methyl-1-propane sulfonic acid and isodecyl methacrylate - potential application as surfactants in micellar-enhanced ultrafiltration processes. Journal of Applied Polymer Science, 106 (3), pp. 1982-1991.

DOI: $\underline{10.1002 / a p p .26891}$

(C) 2007 Wiley Periodicals, Inc. 


\title{
Synthesis and Association Properties in Water Solution of Random Copolymers of 2-Acrylamido-2-methyl-1-propane Sulfonic Acid and Isodecyl Methacrylate-Potential Application as Surfactants in Micellar-Enhanced Ultrafiltration Processes
}

\author{
Carmen Peinado, Fernando Catalina, Verónica San Miguel \\ Instituto de Ciencia y Tecnología de Polímeros, C.S.I.C., C/Juan de la Cierva 3, 28006 Madrid, Spain \\ Correspondence to: C. Peinado (cpeinado@ictp.csic.es).
}

\begin{abstract}
Hydrophobically modified water-soluble polymers have been prepared by copolymerization of 2acrylamido-2-methylpropane sulfonic acid (AMPS) and isodecyl methacrylate (iDMA) in $\mathrm{N}, \mathrm{N}$-dimethylformamide under nitrogen atmosphere, varying the composition feed. Fluorescence spectroscopy was used to further confirm the copolymers self-aggregate in water. Critical concentration of the self-aggregate formation (CAC) decreased by increasing the molar fraction of iDMA in the AMPS $_{\text {co }}$ copolymers and varied between 1.20 and $0.04 \mathrm{~g} / \mathrm{L}$ depending on the degree of hydrophobic modification. Hence, copolymer composition and charge density allowed tuning the pseudomicellar characteristics of these new amphiphilic copolymers. The addition of a salt or a low-molecular-weight surfactant was studied. Binding of CTAB to the $\mathrm{AMPS}_{\mathrm{co}}$ copolymers leads
\end{abstract}

to a high decrease of CAC, i.e., $0.006 \mathrm{~g} / \mathrm{L}$. Effect of the composition in the viscosimetric behavior of the hydrophobically modified copolymers $\mathrm{AMPS}_{\mathrm{co}}$ was investigated. The removal of single metal ions, $\mathrm{Cu}^{2+}$, and $m$-cresol from aqueous solutions by ultrafiltration with the help of the copolymers was investigated. Equilibrium dialysis experiments demonstrate that the formation of hydrophobic microdomains can be used to control the sequestration of foulants, and thus these novel copolymers have potential application as polymeric surfactants in micellar-enhanced ultrafiltration processes for water purification. (C) 2007 Wiley Periodicals, Inc. J Appl Polym Sci 106: 1982-1991, 2007

Key words: polyelectrolytes; association; separation techniques; surfactants; self-assembly

\section{INTRODUCTION}

The understanding of the behavior of polyelectrolytes in dilute solutions of low ionic strength still presents a considerable challenge in macromolecular science in spite of many decades of research. ${ }^{1}$ The characteristic behavior of the hydrophobically modified polyelectrolytes in water is governed by the interplay of electrostatic interactions and the attractive interactions (intra- or/and intermolecular) corresponding to the hydrophobic side chains. In contrast with neutral associating copolymers, the presence of ionic sites of similar charges along the backbone of associating hydrophobically modified polyelectrolytes leads to a great variety of behaviors. ${ }^{2}$

Morishima and coworkers prepared random copolymers of 2-acrylamido-2-methylpropane sul- fonic acid (AMPS) with fluorescently labeled acrylamide comonomers, and their solution properties in water were studied. ${ }^{3,4}$ Also, other authors have prepared random copolymers of AMPS with hydrophobic monomers. ${ }^{5}$ The association behavior of different random copolymers of AMPS was clearly dependent on structural differences of the hydrophobic side chains. ${ }^{6}$ Other critical parameters were identified, such as the sequence distribution of the electrolyte and hydrophobic units together with the type of spacer bond between the hydrophobes and polymer chain. In general, water solution behavior of hydrophobically modified polyelectrolytes depends on structural characteristics as well as external factors, such as ionic strength, $\mathrm{pH}$, and temperature. $\mathrm{pH}$-responsive copolymers based on AMPS were prepared by McCormick and coworkers.

The increasing attraction on amphiphilic polyelectrolytes stems from their potential use in a variety of commercial applications, such as associative thickeners, reology modifiers, polymer-based surfactants, emulsifiers, coagulants, flocculants, and colloids. ${ }^{8,9}$ Interactions between polyelectrolytes and surfactants carrying opposite charges is a matter of current 
interest, mainly because of the fundamental and technological importance of their mixtures. ${ }^{10}$ It is known that the interaction starts as a cooperative association of monomer surfactant to the polymer chain, and micelle-like clusters are formed at the critical aggregate concentration (CAC). Since this interaction is mainly electrostatic, the linear polymer charge density as well as micelle surface charge density play a key role in the associating behavior.

In particular, the self-assembling behavior of amphiphilic polymers in aqueous medium has been shown to be useful for sequestering organic pollutants and heavy metals in urban and industrial wastewater or groundwater. This feature is the basis of micellar-enhanced ultrafiltration (MEUF). The MEUF is a relatively novel separation technique that is based on the addition of surfactants to the solution to be filtered. ${ }^{11}$ Above its critical micellar concentration, the surfactant forms aggregates that may entrap a solute existing in the solution. The increased hydrodynamic size of the solutes enables their rejection by polymeric ultrafiltration membranes. This method is appropriate for binding organic solutes as well as metallic ions, using several attractive forces such as electrostatic or hydrophobic interactions. Moreover, one advantage is that organics and metal ions can be removed simultaneously, provided that the aggregates have a charge opposite that of the target metal ions. This process is typically modeled using equilibrium dialysis (ED) experiments to determine sequestration efficiency for a specific solubilization agent.

The copolymerization of a water-soluble monomer with a low content of a hydrophobic comonomer in a homogeneous solution gives polymers with random distribution of the hydrophobes as isolated units. The growing interest in water-soluble copolymers consisting of a very high molar proportion of hydrophobic side chain is well demonstrated in the literature. $^{12,13}$ In this article, we report the preparation of hydrophobically modified polyelectrolytes by radical copolymerization of AMPS and iDMA at $70^{\circ} \mathrm{C}$ using azobis-isobutyronitrile (AIBN) as initiator in $N, N$-dimethylformamide (DMF) as solvent. Watersoluble copolymers were obtained, incorporating a high molar proportion of i-DMA (up to $35 \mathrm{~mol} \%$ ). The association behavior of random copolymers of sodium 2-(acrylamido)-2-methylpropanesulfonate (AMPS) and dodecyl methacrylate (DMA) was investigated by fluorescence and quasielastic light scattering techniques by Noda and Morishima ${ }^{14}$; however, the hydrophobic content was much lower (1-15 mol \%) than in this study. We have chosen iDMA as hydrophobic monomer to tune the amphiphilic characteristics of these new copolymers, enhancing the hydrophobe content.

Amino derivatives of 7-nitrobenz-2-oxa-1,3-diazole (NBD) were used as fluorescent sensors ${ }^{15}$ to study the associating behavior of amphiphilic copolymers, poly(i-decyl methacrylate-co-sodium 2-acrylamido-2methylpropanesulfonate), in aqueous media.

ED experiments were conducted to evaluate the effects of composition of copolymers on their efficiency in removing metal ions/organic solutes from aqueous solutions. Surfactant role, which is one of the key features of the process, was investigated. Several authors ${ }^{16-18}$ have investigated this micellemediated separation method using low-molecularweight conventional surfactants, i.e., sodium dodecyl sulfate (SDS), while the use of polymeric surfactants has been restricted, mainly to polyethylenglycol type nonionic surfactants. ${ }^{19}$ Therefore, an exploratory study using hydrophobically modified poly-AMPS as surfactants has been carried out.

\section{EXPERIMENTAL}

\section{Materials}

Isodecyl methacrylate (i-DMA), purchased from Aldrich, was distilled under reduced pressure prior to use. 2-Acrylamido-2-methylpropane sulfonic acid (AMPS), and copper(II) chloride dihydrate and $m$ cresol, from Aldrich (Madrid, Spain), and sodium dodecyl sulfate (SDS), Scharlau (Barcelona, Spain), were used as received without further purification.

2,2'-Azobis-isobutyronitrile (AIBN), from Across, was purified by recrystallization from ethanol, prior to be used as initiator of the polymerization. $N, N$ dimethylformamide, from Scharlau, was dried and then distilled under reduced pressure. Amberlite IR120 ion-exchange resin was purchased from Aldrich.

NBD chloride (4-chloro-7-nitrobenz-2-oxa-1,3-diazole), from Aldrich, was used as received. 2-(NMethyl)aminoethanol was purchased from Aldrich and purified by distillation over molecular sieves. All the solvents used on our fluorescence studies were of spectroscopic grade, from Merck. Water was Milli-Q grade, having an initial resistivity of $18.2 \mathrm{~m} \Omega \mathrm{cm}$.

Fluorescent probe (Fig. 1) 4-(N,N-diethyl) amino-7nitrobenz-2-oxa-1,3-diazole (NBD-NEt ${ }_{2}$ ) was synthesized as previously described. ${ }^{15}$ Pyridine 1 (Py-1) and 2-[4-(dimethylamino)styryl]-1-docosylpyridinium bromide (DMASP-Br) were purchased from Aldrich and used as received.

\section{Synthesis of amphiphilic copolymers}

Seven different copolymers in composition were prepared by radical polymerization using AIBN (0.3 wt $\%$ ) in purified DMF as solvent. The comonomers (total monomer concentration, $1 \mathrm{~mol} / \mathrm{L}$ ), AMPS and iDMA, were copolymerized at $70^{\circ} \mathrm{C} \pm 0.1^{\circ} \mathrm{C}$ under $\mathrm{N}_{2}$ atmosphere during $5 \mathrm{~h}$ to reach total conversion. 


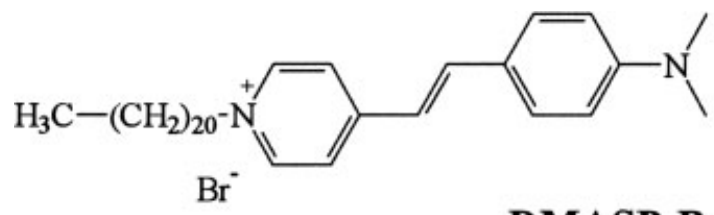

DMASP-Br

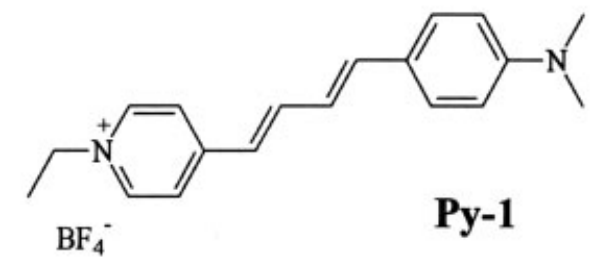<smiles>CCN(CC)c1ccc([N+](=O)[O-])c2nonc12</smiles>

NBD-Et $_{2}$

Figure 1 Structure of the fluorescent probes.

Different feed compositions were used to modify the charge density in the copolymers. All the copolymers were purified by two cycles of solution-precipitation in cold diethyl ether and dried until constant weight. The copolymers were converted into their corresponding sodium salts, using Amberlite IR 120 cation exchange resin, to isolate and store them. The obtained solids in each case were dried by lyophilization. The structure of the copolymers is shown in Figure 2. In the text later, they will be referred as $\operatorname{AMPS}_{\mathrm{co}}(x)$, where $x$ denotes the molar percentage content of the iDMA in the copolymer. The copolymer composition was estimated from elemental microanalysis and from ${ }^{1} \mathrm{H}$ NMR, using the characteristic integral values of the respective monomers. The corresponding homopolymers, $p$-AMPS and $p$ iDMA, were synthesized following the same procedure.

All the copolymers showed the same qualitative ${ }^{1} \mathrm{H}$ NMR and FTIR spectra but different intensities in the signals, depending on their composition. The IR and ${ }^{1} \mathrm{H}$ NMR spectra of copolymers showed the typical peaks found in the homopolymers.

FTIR: $3466 \quad\left(\mathrm{NH}_{\mathrm{AMPS}}\right.$, broad band), 1730 $\left(\mathrm{C}=\mathrm{O}_{\mathrm{iDMA}}\right), \quad 1660 \quad\left(\mathrm{C}=\mathrm{O}_{\mathrm{AMPS}}\right), \quad 1540, \quad 1460,1390$ (iDMA), $1195 \mathrm{~cm}^{-1}$ (st, $\mathrm{S}=\mathrm{O}_{\text {AMPS }}$ ).

${ }^{1} \mathrm{H}$ NMR $\left(\mathrm{D}_{2} \mathrm{O}\right): \delta=6.2\left(\mathrm{NH}_{\mathrm{AMPS}}\right), 4.1\left(\mathrm{CH}_{2}-\right.$ $\left.\mathrm{COO}_{\text {iDMA }}\right), 3.5\left(\mathrm{CH}_{2} \mathrm{SO}_{3 \mathrm{AMPS}}\right), 3.2\left(\mathrm{CH}-\mathrm{C}=\mathrm{O}_{\mathrm{AMPS}}\right)$,
$2.0\left(\mathrm{CH}_{2}-\mathrm{C}_{\text {AMPS }}\right), \quad 1.7\left(\mathrm{CH}-\left(\mathrm{CH}_{3}\right)_{2 \mathrm{DMMA}}\right)$,

( $\left.\mathrm{CH}_{2 \mathrm{iDMA}}\right), 1.4$ ( $\left.\mathrm{CH}_{3 \mathrm{AMPS}}\right), 0.9 \mathrm{ppm}\left(\mathrm{CH}_{3 \mathrm{DMMA}}\right)$.

\section{Characterization and properties study}

Spectral analysis: ${ }^{1} \mathrm{H}$ NMR and ${ }^{13} \mathrm{C}$ NMR spectra were recorded in $\mathrm{D}_{2} \mathrm{O}$ solution on a Bruker AM-400 instrument operated at $400 \mathrm{MHz}$. IR spectra were recorded on a Perkin-Elmer FTIR-spectrophotometer and polymeric samples were examined as $\mathrm{KBr}$ discs. Elemental analysis-nitrogen and sulfur contents were determined by elemental analysis (EA) in a Micro Carlo Erba equipment, model EA 1108.

Optical measurements: UV spectra were recorded by means of a Perkin-Elmer UV-35 spectrophotometer. Fluorescence emission spectra were recorded on a Perkin-Elmer LS-50B spectrofluorimeter. All measurements were performed at ambient temperatures. To improve accuracy in the determination of maximum wavelengths, first derivative spectra were obtained in all the wide emission bands. Sample solutions were prepared by dissolving a known amount of polymer in water. As employed fluorescent probes exhibit low solubility in water, stock solutions were prepared in ethanol. The stock solution $\left(2.2 \times 10^{-3} M\right)$ was added into the examined polymer water solutions of a given concentration in amount not higher than $1.5 \mathrm{vol} \%$, and the solutions were allowed to stand for 1 day for equilibration. The effective concentration of the probes was maintained at $4 \times 10^{-6} \mathrm{M}$ in all the aqueous solutions. Fluorescence emission spectra of the probes were

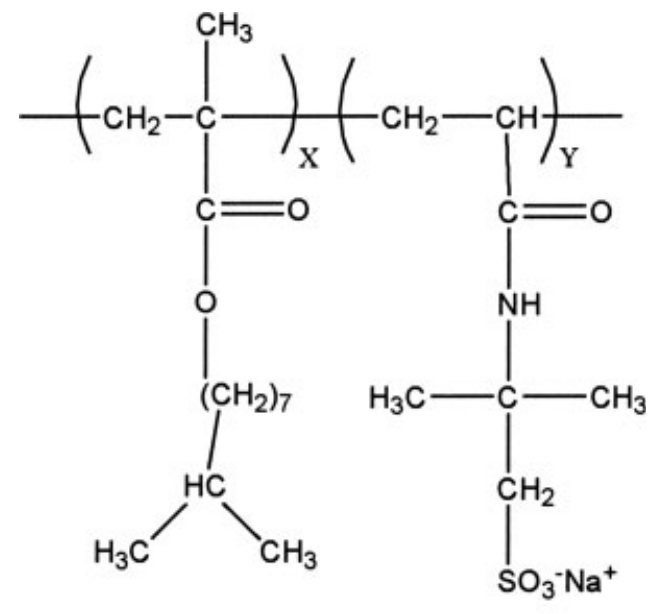

\section{$\operatorname{AMPS}_{\mathbf{c} 0}(\mathbf{x})$}

Figure 2 Structure of amphiphilic copolymers of isodecyl methacrylate (iDMA) and sodium 2-acrilamido-2-methylpropane sulfonate (AMPS). The copolymers were noted as $\operatorname{AMPS}_{\mathrm{co}}(x)$, where $x$ is the molar fraction of the iDMA in the copolymer. 
recorded in the range of $490-700 \mathrm{~nm}$ using a fixed excitation wavelength of $477 \mathrm{~nm}$. Under such conditions, only one single fluorescence emission peak was observed. All the spectra were corrected using the response curve of the photomultiplier.

Gel permeation chromatography: Gel permeation chromatography (GPC) was carried out using a Waters 1515 Isocratic Pump system equipped with a differential refractive index Waters 2414. The mobile phase was $0.1 \mathrm{M} \mathrm{NO} \mathrm{NO}_{3} \mathrm{~K}$ solution containing acetonitrile $15 \mathrm{vol} \%$ and the flow rate was set at $0.5 \mathrm{~mL} /$ $\mathrm{min}$. The system was equipped with a guard column and two columns. Ultrahydrogel 500 and 250 (Waters) columns were used as hydrophilic columns. The refractive index detector was thermostatized at $30^{\circ} \mathrm{C}$. Samples were dissolved in MilliQ water, and the concentration of probes was $1.5 \mathrm{mg} / \mathrm{mL}$ and the volume was $50 \mu \mathrm{L}$. Millipore-disposable filters of pore size $0.45 \mu \mathrm{m}$ were used to remove dust particle from sample solutions and the solvent. Poly(ethylene oxide) standards $\left(M_{p}=2.2 \times 10^{4}-8.4 \times 10^{5} \mathrm{~g} / \mathrm{mol}\right.$, Waters) were used for calibration curve. Breeze software was used for data processing.

Viscosimetric measurements: Viscosimetric measurements were carried out at $30^{\circ} \mathrm{C}$ with an Ubbelohde microviscosimeter having a $0.40-\mathrm{mm}$ capillary diameter and an instrument constant of $0.01 \mathrm{~mm}^{2} / \mathrm{s}^{2}$. The viscosimeter was placed into an automatic viscosimeter AVS 350, from Schott. All the polymer solutions were made up in Mili-Q water. The polymers were allowed to hydrate and swell for at least $24 \mathrm{~h}$ at ambient temperature, and then the solutions were very gently stirred to form homogeneous solutions. The solutions were filtered through $0.45-\mu \mathrm{m}$ filters to remove dust and other traces of impurities. Before the measurements were carried out, the samples were allowed to equilibrate for $10 \mathrm{~min}$ to ensure that thermal equilibrium was reached.

Equilibrium dialysis experiments: ED experiments are useful to predict, almost quantitatively, MEUF separation results for the removal of ionic or molecular solutes. ${ }^{20}$ Therefore, the experiments for removal of pollutants were performed using dialysis cells (6 $\mathrm{mL})$, as ED is a simple experimental method. Each cell consists of two sides covered with regenerated cellulose membranes (CelluSept2 from Spectrapore) with a diameter of $30 \mathrm{~mm}$ and a total filter surface area of $707 \mathrm{~mm}^{2}$. The molecular weight cutoff (MWCO) for the membranes is $6000-8000$ Da. Membranes were soaked in water for $1 \mathrm{~h}$ prior to use. The temperature was held constant at $25^{\circ} \mathrm{C}$.

Copolymer concentrations were chosen above their corresponding CAC, $\left[\right.$ AMPS $\left._{\mathrm{co}}(11)\right]=1.5 \mathrm{~g} / \mathrm{L}$; $\left[\operatorname{AMPS}_{\mathrm{co}}(20)\right]=0.6 \mathrm{~g} / \mathrm{L}$ and $[\operatorname{AMPS}(30)]=0.6 \mathrm{~g} / \mathrm{L}$. The concentration of pollutants was varied between 5 and $70 \mathrm{mM}$. Feed sample solutions were prepared by dissolving a known amount of polymer in water and adding the required amounts of $\mathrm{Cu}^{2+}$ or $m$-cresol. The dialysis cell was initially filled with $6 \mathrm{~mL}$ of feed solution. The equilibration period was $24 \mathrm{~h}$, determined in dialysis experiments in the absence of polymer. The concentration of $\mathrm{Cu}^{2+}$ or $m$-cresol of the permeate samples at the desired time intervals were analyzed spectroscopically using a UV-vis spectrophotometer (Lamda 35, Perkin-Elmer) at a wavelength of $800 \mathrm{~nm}$ for $\mathrm{Cu}^{2+}$ and $285 \mathrm{~nm}$ for $\mathrm{m}$ cresol. To investigate the effect of sodium chloride, some experiments were performed with the same concentrations of sodium chloride added to the retentate and the permeate solutions.

The overall efficiency of the foulant sequestration may be evaluated from the percent of rejection ratio which is defined as

$$
R=100\left(1-[\mathrm{M}]_{p} /[\mathrm{M}]_{r}\right)
$$

where $[\mathrm{M}]_{p}$ and $[\mathrm{M}]_{r}$ denote the concentrations of solute (metal ions or $m$-cresol) in permeate and retentate, respectively. Therefore, the rejection ratio is a measure of how well the polymer prevents passage of the foulant through the membrane. High values indicate that the polymer domain is capable of interacting with and retaining the foulant.

The binding molar fraction $(r)$ reflects the interaction between the solute and the surfactant on a molecular basis and was determined from Eq. (2):

$$
r=\left[\text { solute }_{b} /[\text { surfactant }]\right.
$$

where [surfactant] is the concentration of polymer in the retentate. Binding isotherms may be built by plotting $r$ as a function of feed foulant concentration.

\section{RESULTS AND DISCUSSION}

\section{Synthesis of the copolymers of AMPS and IDMA}

Free radical copolymerization of iDMA with AMPS was carried out at $70^{\circ} \mathrm{C} \pm 0.1^{\circ} \mathrm{C}$ in DMF solution, using AIBN as initiator. The molar fraction of AMPS in the feed, $f_{\mathrm{AMPS}}$, ranged from 0.9 to 0.6 , using 1.0 $\mathrm{mol} / \mathrm{L}$ as total monomer concentration (Table I). The hydrophobic content in the hydrophilic/hydrophobic polymers is limited by their solubility in water. Reaction was carried out until total conversion was reached, but yields of polymer were between $82 \%$ and $100 \%$. The conversion of these copolymers containing acid groups into their corresponding salts was carried out quantitatively using a cationexchange resin. This procedure resulted in polyacrylamides containing hydrophobic groups along the chain.

In comparison with other synthetic procedures for preparation of amphiphilic polymers, the employed 
TABLE I

Molar Fraction of Sodium 2-(Acrylamido)-2methylpropane Sulfonate in the Feed ( $\left.f_{\text {AMPS }}\right)$ and in the Copolymer $\left(F_{\text {AMPS }}\right)$ Determined by Elemental Analysis and ${ }^{1} \mathbf{H}$ NMR, the Number-Average Molar Mass $\left(M_{n}\right)$, Polydispersity $\left(M_{w} / M_{n}\right)$, and the Yield of the Reaction

\begin{tabular}{|c|c|c|c|c|c|c|}
\hline \multirow[b]{2}{*}{ Copolymer } & \multirow[b]{2}{*}{$f_{\text {AMPS }}$} & \multicolumn{2}{|c|}{$F_{\text {AMPSco }}$} & \multirow[b]{2}{*}{$M_{n}$} & \multirow[b]{2}{*}{$M_{w} / M_{n}$} & \multirow{2}{*}{$\begin{array}{c}\text { Yield } \\
(\%)\end{array}$} \\
\hline & & EA & NMR & & & \\
\hline $\operatorname{AMPS}_{\mathrm{co}}(11)$ & 0.90 & 0.89 & 0.89 & 24,480 & 2.50 & 99 \\
\hline AMPS $_{\mathrm{co}}(18)$ & 0.85 & 0.82 & 0.88 & 19,200 & 2.84 & 92 \\
\hline $\mathrm{AMPS}_{\mathrm{co}}(20)$ & 0.80 & 0.80 & 0.87 & 19,500 & 3.13 & 85 \\
\hline AMPS $_{\mathrm{co}}(26)$ & 0.75 & 0.74 & 0.81 & 17,560 & 2.59 & 82 \\
\hline $\mathrm{AMPS}_{\mathrm{co}}(30)$ & 0.70 & 0.70 & 0.67 & 24,300 & 2.36 & 98 \\
\hline $\mathrm{AMPS}_{\mathrm{co}}(37)$ & 0.65 & 0.63 & 0.67 & 23,500 & - & 95 \\
\hline $\mathrm{AMPS}_{\mathrm{co}}(35)$ & 0.60 & 0.65 & & 22,500 & - & 90 \\
\hline
\end{tabular}

Free radical copolymerizations of AMPS with iDMA were carried out at $70^{\circ} \mathrm{C}$ in DMF under nitrogen atmosphere. Total monomer concentration was $1 \mathrm{~mol} / \mathrm{L}$.

free radical copolymerization in a cosolvent has several advantages. Among them, higher tolerance to moisture and other impurities has to be remarked, which makes this synthetic route the most suitable from an industrial viewpoint.

The molar fraction of sodium 2-(acrylamido)-2methylpropane sulfonate in the copolymer, $F_{\mathrm{AMPS}}$, was determined by EA. Also, the copolymer composition was estimated from the ratio of integrals of well-separated characteristic comonomers peaks, i.e., $0.9 \mathrm{ppm}$, end $\mathrm{CH}_{3}$ of isodecyl and $2 \mathrm{ppm}, \mathrm{CH}_{2}$ of AMPS. The data are summarized in Table I, together with the number-average molar mass determined by GPC.

The molar fractions of AMPS in the copolymers by NMR are slightly higher than those by EA. This feature may be associated to the solvent selectivity of copolymers in water. Molecular characterization (molecular weight and molecular weight distribution) of associating polymers is rather difficult because of phase separation in dilute region. However, the use of acetonitrile as cosolvent probably improves the solubility of these $\mathrm{AMPS}_{\mathrm{co}}$ copolymers, allowing the GPC analysis. The low ability of acetonitrile to form $\mathrm{H}$-bonds leads to a partial disruption of the water structure ${ }^{21}$ and weakens the hydrophobic aggregation existed in solutions in the course of the chromatography. Moreover, the presence of salt allows the screening of the charges of polyelectrolyte to minimize ionic interactions and allows coil formation in the polymer chain. The synthesized copolymers are monomodal and have no variation in the length of the hydrophobic chain. It is expected that compositional, structural, and molecular weight heterogeneity, which contribute to the deterioration of rheological properties of associating polymers (thickening), may be ruled out.
Microdomain formation of amphiphilic copolymers AMPS $_{\text {co }}$ in water solutions

The amphiphilic nature of the copolymers, consisting of hydrophilic AMPS and hydrophobic iDMA, provides an opportunity to form aggregates in water. We have used several fluorescent probes for monitoring viscosity and polarity changes during photopolymerization. Here, intramolecular charge transfer probes and organic salts were used to determine CAC. Figure 3 plots the variation of the ratio $\phi_{f} / \phi_{\text {fo }}$ versus the hydrophobically modified polyelectrolyte concentration, where $\phi_{\mathrm{fo}}$ is the fluorescence quantum yield of the probe in pure water and $\phi_{f}$ is the same in polymeric solutions. The ionic fluorescent probes DMASP-Br and Py-1 contain an anionic contraion that favors the formation of the hydrophobic aggregates due to cooperative effect. Therefore, fluorescence intensity ratio increase starts at lower copolymer concentration than that of NBD neutral fluorescent probe. It is reasonable to consider that the copolymer undergoes certain intramolecular aggregation below the CAC, because the binding of the probe is accompanied by changes in the intensity as observed below CAC. While NBD fluorescence does not change for low copolymer concentration a steadily emission change is observed with DMASP-Br and Py-1. Then, for all the probes, a sharp fluorescence change occurs at $C A C$, which is the minimum concentration for the formation of the hydrophobic microdomains.

Therefore, NBD amino derivative was selected as extrinsic fluorescent probe for studying the associative behavior of the amphiphiles AMPS $_{\text {co }}$ in water (Fig. 4). In all cases, there was a strong increase of the $\phi_{f} / \phi_{\mathrm{fo}}$ ratio that corresponded to the onset of the self-assembly behavior which is typical for amphiphilic

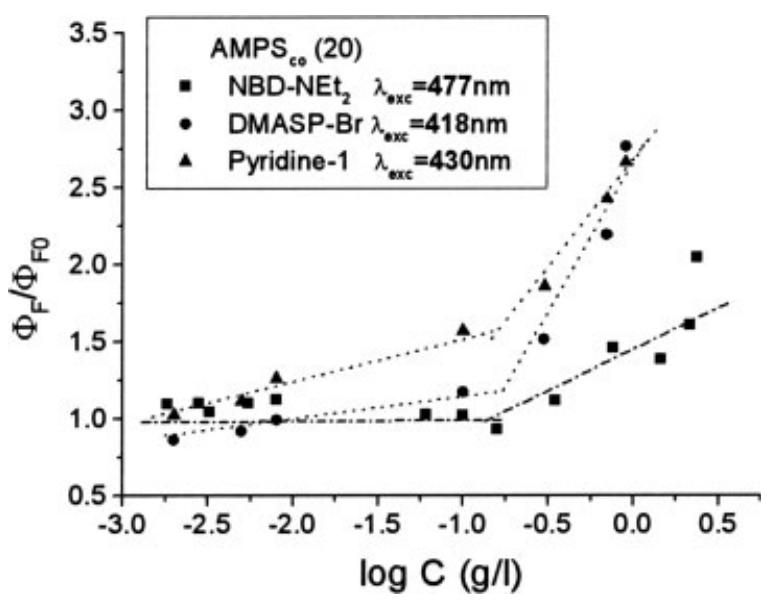

Figure 3 Variation of the quantum yield ratio $\phi_{f} / \phi_{\text {fo }}$ as a function of the $\operatorname{AMPS}_{\mathrm{co}}(20)$ concentration at room temperature. NBD-NEt ${ }_{2}$, DMASP-Br, and Py-1 were used as fluorescent probes. 


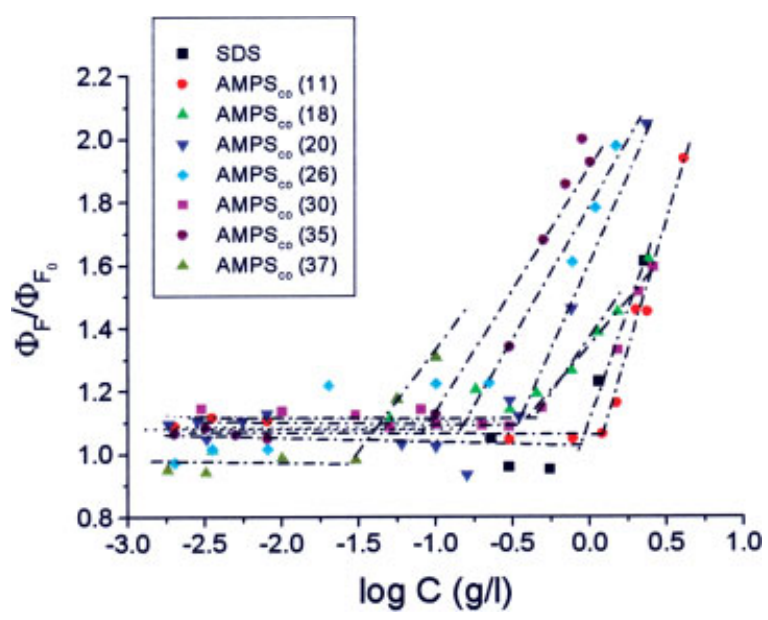

Figure 4 Plot of the fluorescence quantum yields ratio, $\phi_{f} / \phi_{\mathrm{fo}}$, as a function of the copolymer concentration at room temperature. SDS was used as reference. [Color figure can be viewed in the online issue, which is available at www.interscience.wiley.com.]

polymers in water solutions. A comparative evaluation of $\phi_{f} / \phi_{\mathrm{fo}}$ suggests that these polymeric solutions provide nonpolar microdomains, similar to those of simple surfactants like SDS aggregates. The formation of hydrophobic microregions (domains) in aqueous media and the penetration of NBD derivative into these domains leads to an increase of fluorescence intensity emission accompanied by a solvatochromic shift.

CAC was determined as the onset of the $\phi_{f} / \phi_{\mathrm{fo}}$ increase as a function of the concentration and the data are summarized in Table II. Characteristic features of aqueous solutions of polymers under study are the low CAC and the relatively broad transition range, where $\phi_{f} / \phi_{\mathrm{fo}}$ value increases. CAC values determined in this way were of $\sim 4 \times 10^{-2}-1.2 \mathrm{~g} /$ L. The higher is the content of hydrophobic units, the lower the value of CAC. The water-soluble copolymer with the highest molar fraction of incorporated hydrophobic chain, AMPS(37), exhibits an

TABLE II

Minimal Concentration for the Aggregation (CAC) of the

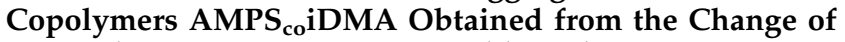
Fluorescence Quantum Yields and Maximum Fluorescence Shifts

\begin{tabular}{llc}
\hline & \multicolumn{2}{c}{ CAC $(\mathrm{g} / \mathrm{L})$} \\
\cline { 2 - 3 } $\mathrm{AMPS}_{\mathrm{co}} \mathrm{iDMA}$ & $\lambda$ & $\Phi$ \\
\hline $\mathrm{AMPS}_{\mathrm{co}}(11)$ & 1 & 1.20 \\
$\mathrm{AMPS}_{\mathrm{co}}(18)$ & 0.56 & 0.50 \\
$\mathrm{AMPS}_{\mathrm{co}}(20)$ & 0.42 & 0.32 \\
$\mathrm{AMPS}_{\mathrm{co}}(26)$ & 0.24 & 0.22 \\
$\mathrm{AMPS}_{\mathrm{co}}(30)$ & 0.35 & 0.32 \\
$\mathrm{AMPS}_{\mathrm{co}}(35)$ & 0.10 & 0.10 \\
$\mathrm{AMPS}_{\mathrm{co}}(37)$ & 0.05 & 0.04 \\
\hline
\end{tabular}

CAC for AMPS ${ }_{\mathrm{co}}$ BuMA are shown for comparison. almost zero CAC, in view of the formation of nonpolar microdomains at concentration as low as $4 \times$ $10^{-2} \mathrm{~g} / \mathrm{L}$.

Moreover, the maximum emission wavelength was blueshifted when concentration of copolymer was increased. This variation also reflected by the gradual formation of hydrophobic microdomains. From the plot $\lambda_{\max }$ versus $\log C$, it was possible to determine the onset of microdomain formation put in evidence by the drastic slope change corresponding to CAC. The minimal concentration for the microdomain formation, CAC, of the copolymers AMPS $_{\text {co }}$ is collected in Table II and compared with those obtained from the change of fluorescence quantum yields. Both sets of values show good agreement with each other, indicating that the formation of pseudoaggregates causes severe changes, both in polarity (change of maximum wavelength) and microviscosity (change of fluorescence intensity). The solubilization site of the probe is dependent on polymer concentration and also on hydrophobic level. The $\lambda_{\max }$ shifts are smaller for copolymers with low hydrophobic modification. This difference might be attributed to the solubilization of the probe closer to the surface and more exposed to water. For comparison, the value of critical micellar concentration for the well-known surfactant SDS was determined, in the same way by fluorescence, and was in agreement with the reported value ${ }^{22}(0.923 \mathrm{~g} / \mathrm{L})$, whereas much lower values were obtained with the copolymers AMPS $_{\mathrm{co}}$ iDMA.

Salt effect on fluorescence was studied. In general, addition of sodium chloride exhibits a salting-out effect. The influence of a cosurfactant CTAB was also studied (Table III).

The introduction of an ionic atmosphere effected in the presence of $\mathrm{NaCl}$ plays a significant role in modifying electrostatic forces, and influence the participation of $\mathrm{C}_{10}$ chains in microdomain formation. Moreover, the interaction between the copolymers and the low-molecular-weight cationic surfactant CTAB leads to the formation of complexes. Electrostatic interactions are generally believed to be the primary driving forces for the formation of the complexes. This pattern seems very likely in systems where both partners bear opposite charge. On the

TABLE III

Minimal Concentration for the Microdomain Formation (CAC) of the Copolymers AMPS co $_{\text {in the Absence and }}$ Presence of $\mathrm{NaCl}(1 M)$ and CTAB $(0.04 \mathrm{~g} / \mathrm{L})$

\begin{tabular}{lccc}
\hline & \multicolumn{3}{c}{$\mathrm{CAC}(\mathrm{g} / \mathrm{L})$} \\
\cline { 2 - 4 } Polyelectrolyte & No additives & $\mathrm{NaCl}$ & $\mathrm{CTAB}$ \\
\hline $\mathrm{AMPS}_{\mathrm{co}}(11)$ & 1.2 & 0.42 & 0.006 \\
$\mathrm{AMPS}_{\mathrm{co}}(20)$ & 0.32 & 0.10 & - \\
$\mathrm{AMPS}_{\mathrm{co}}(30)$ & 0.25 & 0.07 & - \\
\hline
\end{tabular}


other hand, as the polyelectrolyte contains hydrophobic groups anchored along the backbone, the association with $\mathrm{CTAB}$ may arise mainly from hydrophobic interactions. Figure 5 shows the change of fluorescence emission versus the logarithm of the copolymer $\mathrm{AMPS}_{\mathrm{co}}(11)$ concentration, at a fixed CTAB concentration $(0.04 \mathrm{~g} / \mathrm{L})$. At low polymer concentration, fluorescence intensity ratio slightly increases while there is an abrupt increase when the polymer concentration is beyond a certain value. The CAC has been estimated from the intersection point of the tangent lines to each portion of the curve. An hydrophobic modification level as low as $11 \%$ of $C_{10}$ dangling groups is large enough to promote association of the copolymer $\mathrm{AMPS}_{\mathrm{co}}(11)$ and $\mathrm{CTAB}$ at much lower concentration $(0.006 \mathrm{~g} / \mathrm{L})$ than in the presence of salt or varying the content of hydrophobic monomer.

The binding of surfactants to hydrophobically modified polymers (HMP) is analogous to the mixed micellization in mixed surfactant solutions as far as HMP behaves and, therefore, may be considered as a modified surfactant. The interactions of ionic surfactants with oppositely charged polyelectrolytes that are hydrophobically modified lead to a high degree of binding and mixed aggregates often formed between the surfactant and side chains at concentrations well below the critical micellar concentration. ${ }^{23}$ Different stages were observed in the studied system (Fig. 5). At low polymer amounts, increasing the concentration results in an increase of fluorescence emission up to a maximum value is reached at $1: 1$ stoichiometry (equivalent charge between surfactant and polyelectrolyte chains) of the surfactant-polymer complex. Characteristic properties of HMP/surfactant mixtures may be related to stoichiometries of the mixed complexes. Fluorescence intensity enhance has been related to an initial

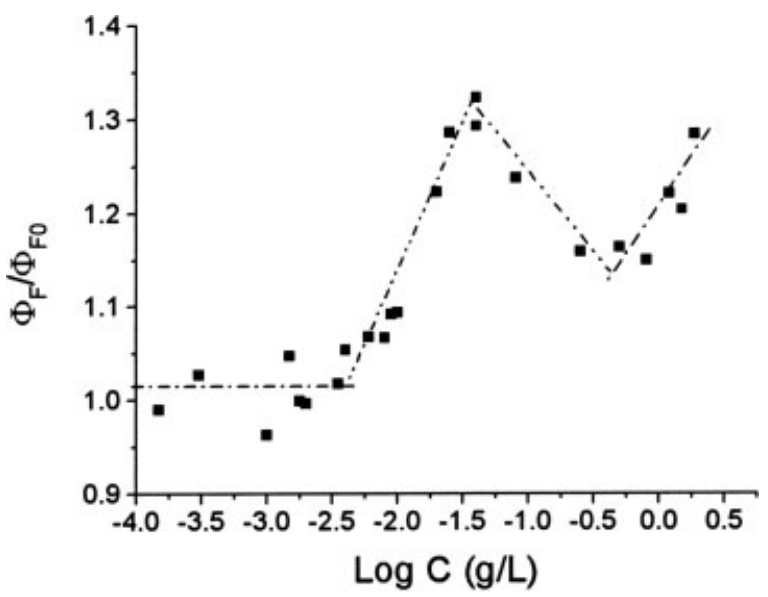

Figure 5 Change of fluorescence emission versus the logarithm of the copolymer concentration at a fixed CTAB concentration $(0.04 \mathrm{~g} / \mathrm{L})$.

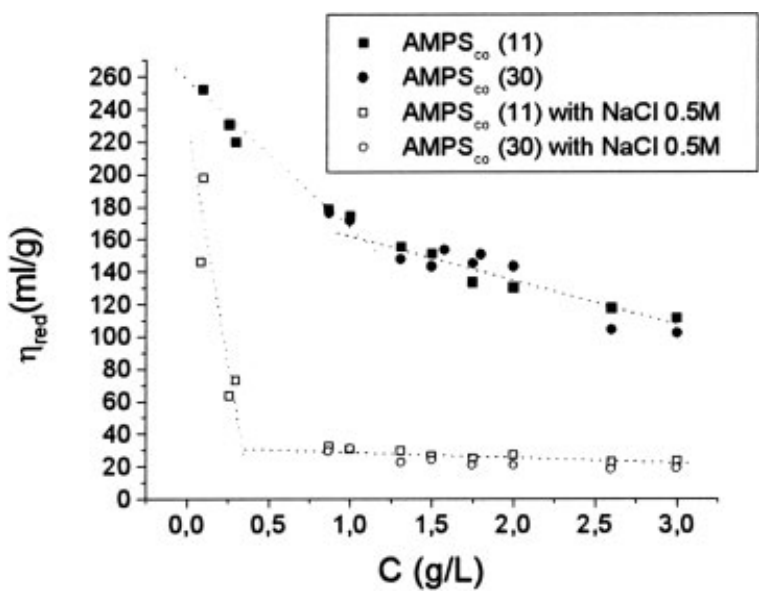

Figure 6 Variation of the reduced viscosity, $\eta_{\mathrm{sp}} / \mathrm{C}$, versus polymer concentrations, in aqueous solutions without salt (solid symbols) and in the presence of $0.5 \mathrm{M} \mathrm{NaCl}$ (open symbols).

increase in solution viscosity up to a maximum. ${ }^{24}$ Further addition of polymer leads to a rapid decrease of fluorescence which may be related to a phase separation phenomena and disruption of aggregates formation, taking into account that copolymer does not quench the fluorescence. However, no precipitation was observed provided that the concentration of cetyltrimethylammonium bromide is still lower than the CAC. At higher polymer concentrations, cooperative binding results in a rapid increase of fluorescence intensity.

\section{Viscosity characteristics of polymer solutions}

Effect of the composition in the viscosimetric behavior of the hydrophobically modified copolymers $\mathrm{AMPS}_{\text {co }}$ was investigated. The solution viscosity of copolymers was determined over a wide concentration range, in saltless and salt-containing aqueous solutions.

Figure 6 presents the variation of the reduced viscosity, $\eta_{\mathrm{sp}} / C$, versus the concentration of the polymers under study, in aqueous solutions without salt and in the presence of $\mathrm{NaCl}(0.5 \mathrm{M})$. The viscosity of the aqueous solutions is characteristically low up to high polymer contents. A typical polyelectrolyte behavior is observed, i.e., the $\eta_{\mathrm{sp}} / C$ values increase with copolymer concentration decrease because of the expansion of the macroion chain, which is caused by the progressively enhanced dissociation of ionizable groups and hence intensification of the intramolecular repulsive interactions between ionized groups spread all along the chain. At higher polymer concentrations, the effective ionic strength raises, and a gradual screening of the electrostatic interactions occurs resulting in chain contraction. In contrast, no significant differences were found due 
to the influence of the hydrophobic group content in the studied range of polymer concentration.

Owing to their polyelectrolyte character, $\mathrm{AMPS}_{\mathrm{co}}$ copolymers are responsive to changes in ionic strength. The addition of salt to the solutions results in a drop of the reduced viscosity of the copolymer solutions in water. The presence of a salt brings about the screening of electrostatic interactions and the weakening of the dissociation along the polyion backbone; consequently the Coulomb repulsive interactions between the ionized groups decrease, allowing the chain to coil more tightly. In the other hand, at intermolecular level, the macromolecular interpenetration is facilitated by adding salt and thus promotes enhanced polymolecular associations.

From the plot of reduced viscosity versus concentration the onset of microdomain formation was determined for $\mathrm{AMPS}_{\mathrm{co}}(11)$ at $1.1 \mathrm{~g} / \mathrm{L}$; while in the presence of $\mathrm{NaCl}(0.5 \mathrm{M})$, the minimum aggregation concentration was reduced at $0.35 \mathrm{~g} / \mathrm{L}$. These values agree well with those obtained by fluorescence method.

The intrinsic viscosity was obtained by the Fedors ${ }^{25}$ method applying the Eq. (3):

$$
1 /\left[2\left(\eta_{r}^{1 / 2}-1\right)\right]=1 /[\eta] C-1 /[\eta] C_{m}
$$

where [ $\eta]$ is the intrinsic viscosity and $C_{m}$ is the polymer concentration parameter.

In the presence of salt, Fedors equation does not give an straight line, therefore, it was not possible to calculate the intrinsic viscosity. Overlap concentration $\left(C^{*}\right)$ is the concentration at which polymer coils begin to overlap each other, separating semidilute and dilute regions. $C^{*}$ was estimated as the reciprocal of intrinsic viscosity $\left(C^{*}=1 /[\eta]_{\text {Fedors }}\right){ }^{26}$ For $\mathrm{AMPS}_{\mathrm{co}}(11)$ and (30), the overlap concentration values were estimated as $C^{*}=2.8 \mathrm{~g} / \mathrm{L}$ and $2.6 \mathrm{~g} / \mathrm{L}$, respectively. These concentrations are higher than those for critical aggregation ones, indicating that the hydrophobic microdomain formation occurs in the dilute regime.

\section{Binding of organic compounds and metal ions}

To study the composition-dependent sequestration of $\mathrm{Cu}^{2+}$ or $m$-cresol by AMPS ${ }_{\text {co }}$ copolymers, equilibrium dialysis experiments were performed at $25^{\circ} \mathrm{C}$. The experiments were carried out using surfactant concentrations $0.3 \mathrm{~g} / \mathrm{L}$ higher than $\mathrm{CAC}$, i.e., $1.5 \mathrm{~g} / \mathrm{L}$ for $\mathrm{AMPS}_{\mathrm{co}}(11)$ and $0.6 \mathrm{~g} / \mathrm{L}$ for $\mathrm{AMPS}_{\mathrm{co}}(20)$ and (30), in the absence and in the presence of $\mathrm{NaCl} 1 \mathrm{M}$.

Binding isotherms for $\mathrm{AMPS}_{\mathrm{co}}(11)$ and $\mathrm{AMPS}_{\mathrm{co}}(30)$ with $\mathrm{Cu}^{2+}$ and $m$-cresol are shown in Figure $7(\mathrm{a}, \mathrm{b})$, respectively. The effect of salt addition was also investigated. The binding isotherms indicate that
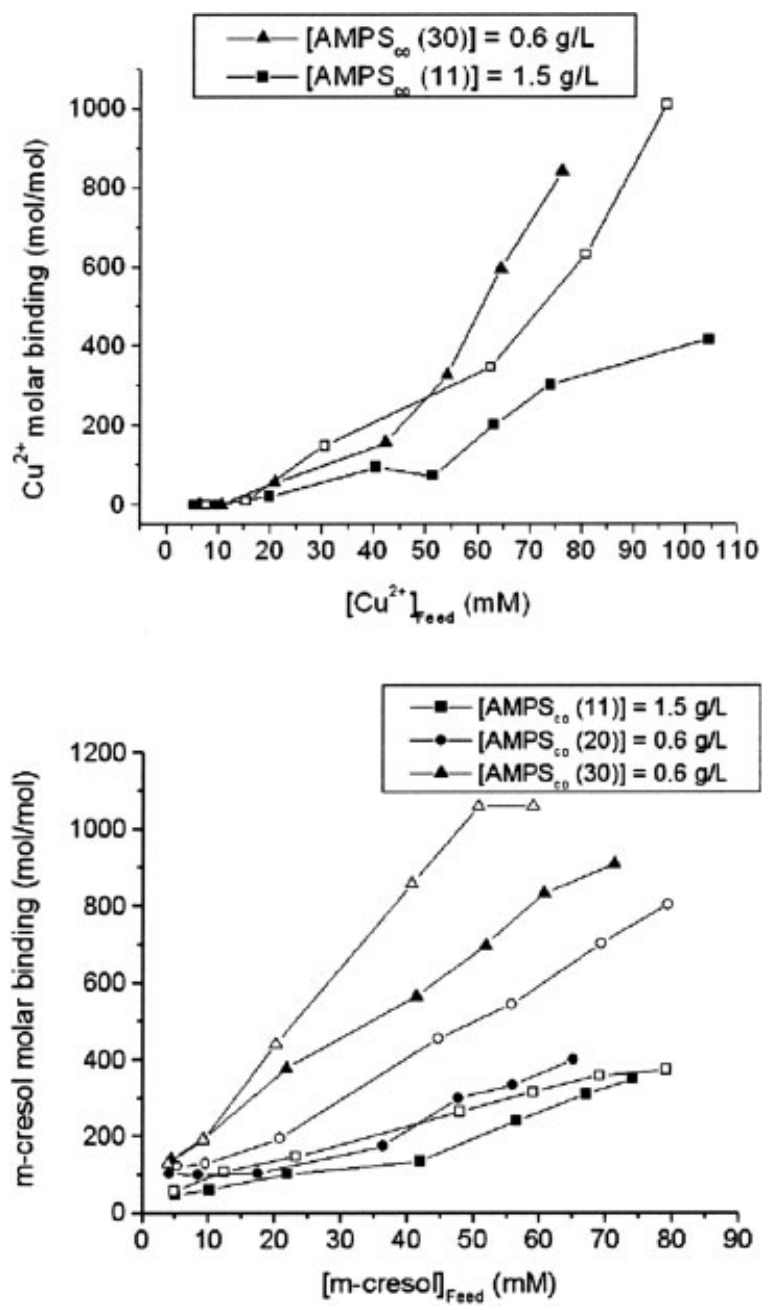

Figure 7 Binding isotherms for $\mathrm{AMPS}_{\mathrm{co}}$ copolymers and (a) $\mathrm{Cu}^{2+}$ or (b) $m$-cresol, in aqueous solutions without salt (solid symbols) and in the presence of $1 \mathrm{M} \mathrm{NaCl}$ (open symbols), as a function of $m$-cresol concentration.

sequestration of both foulants occurs throughout the whole range of concentrations investigated.

In the case of $m$-cresol, the molar binding increases in a linear fashion for all the copolymers, whereas at a $\mathrm{Cu}^{2+}$ concentration of feed of $40-50 \mathrm{mM}$, a step increase in the molar binding occurs. It appears that $\mathrm{Cu}^{2+}$ in the solution promotes a change in the domain organization (aggregation number or polymer conformation), such that significantly higher loadings of $\mathrm{Cu}^{2+}$ can be accommodated. This change is less pronounced and occurs at higher $\mathrm{Cu}^{2+}$ concentration for $\mathrm{AMPS}_{\mathrm{co}}(11)$ compared with $\mathrm{AMPS}_{\mathrm{co}}(30)$, indicating the role of the hydrophobic modification level in aggregation and thus metal ion sequestering. This feature is also confirmed by the higher $m$-cresol molar binding by increasing the hydrophobic level in the copolymers, which points out that the interaction of polymer with $m$-cresol is favored with a higher content of iDMA. Also these results point out 
TABLE IV

Rejection Ratios as a Function of $\left[\mathrm{Cu}^{2}\right]_{\text {feed }}$ for AMPS(11) and AMPS(30) Copolymers

\begin{tabular}{|c|c|c|c|}
\hline \multirow[b]{2}{*}[\mathrm{Cu}^{2+}]{$(\mathrm{mM})$} & \multicolumn{2}{|c|}{$\operatorname{AMPS}_{\mathrm{co}}(11)$} & \multirow{2}{*}{$\frac{\operatorname{AMPS}_{\mathrm{co}}(30)}{\text { No salt }}$} \\
\hline & No salt & $1 M \mathrm{NaCl}$ & \\
\hline 6 & 0 & 0 & 0 \\
\hline 10 & 0 & 4 & 0 \\
\hline 20 & 7 & 32 & 7 \\
\hline 42 & 15 & 36 & 10 \\
\hline 54 & 9 & 50 & 24 \\
\hline 64 & 21 & 66 & 29 \\
\hline 75 & 27 & - & - \\
\hline
\end{tabular}

that the $\mathrm{Cu}^{2+}$ binding is related not only to cation binding as could be expected due to a favored interaction between this cation and the anionic polyelectrolytes $\mathrm{AMPS}_{\mathrm{co}}$. The charge-screening effect of the salt enhances the molar binding for both $\mathrm{Cu}^{2+}$ ions and $m$-cresol.

To evaluate potential application of these copolymers in a MEUF application, rejection ratios were calculated for each copolymer under various environmental conditions. Rejection ratios indicate the percentage of small solutes retained within hydrophobic domains and/or, in the case of $\mathrm{Cu}^{2+}$, captured by the sulfonate group of the copolymers. Table IV shows the percent of rejection of $\mathrm{Cu}^{2+}$ versus ions concentration in the feed, using the copolymers $\mathrm{AMPS}_{\mathrm{co}}(11)$ or $\mathrm{AMPS}_{\mathrm{co}}(30)$ as surfactants. Since $\mathrm{AMPS}_{\mathrm{co}}$ copolymers dissociate in aqueous phase and possess negative charges, it can be expected that these anionic polyelectrolytes will be effective to attract positive $\mathrm{Cu}^{2+}$ ions onto the aggregates. There is a slight increase in the rejection with the increase of hydrophobic modification in the copolymer for the higher $\mathrm{Cu}^{2+}$ concentrations.

The presence of salt affects the effectiveness on metal rejection. In general, increasing electrolyte concentration leads to compression of the electrical double layer and to counteraction of the charge of the aggregates, and thus reduction in the electrostatic attraction between ions and the aggregates. As a result, the nontrapped metals in solution pass through the membrane leading to lower rejection. ${ }^{27}$ However, it is observed that the rejection factor enhances in the presence of $\mathrm{NaCl}$ in this study. This feature is attributed to the decrease of CAC in the presence of salt. Thus, one may expect a higher fraction of aggregates in the presence of salt than for the pure surfactant, which may compensate for the less negative charges and result in a $\mathrm{Cu}^{2+}$ rejection factor higher than this obtained in the absence of salt. Moreover, this behavior points out the significant role of hydrophobic modification for sequestering $\mathrm{Cu}^{2+}$ ions.

Table $\mathrm{V}$ collects the percentages of rejection of $m$ cresol versus $m$-cresol concentration in the feed, where the copolymers $\mathrm{AMPS}_{\mathrm{co}}$ were employed as surfactants. The lower rejection factor of $m$-cresol as its feed concentration increases may be due to a weak tendency to be solubilized in the aggregates, which is inferred from the relatively hydrophilic characteristic, with a solubility of $23.5 \mathrm{~g} / \mathrm{L}$ at $20^{\circ} \mathrm{C}$. The formation of mixed aggregates with CTAB leads to a higher rejection ratios.

The percentage of rejection increased remarkably with increase in the hydrophobic content from $\mathrm{AMPS}_{\mathrm{co}}(11)$ to $\mathrm{AMPS}_{\mathrm{co}}(30)$; whereas $\mathrm{AMPS}_{\mathrm{co}}(20)$ showed the lowest values. Molecular weight of surfactant also plays a key role, i.e., the shorter the chain length, the lower the force needed to go through the membrane. Therefore, it is not surprising that $\mathrm{AMPS}_{\mathrm{co}}(20)$, which has the lowest molecular weight (as shown in Table I) and also more close to the MWCO, showed the lowest rejection ratio. $\mathrm{AMPS}_{\mathrm{co}}(11)$ and (30) had similar molecular weight and, thus, the differences in sequestering organic compounds are related to hydrophobic level in the polyelectrolyte.

The rejection percentages decreased as foulant concentration in the feed increases for the low $m$-cresol concentration and then, leveled off asymptoti-

TABLE V

Rejection Ratios as a Function of $[m \text {-cresol }]_{\text {feed }}$ for $\operatorname{AMPS(11),~(20),~and~}$

(30) Copolymers

\begin{tabular}{|c|c|c|c|c|c|c|c|}
\hline \multirow{2}{*}{$\begin{array}{c}{\left[m-{ }_{\text {-Cresol }}\right]_{\text {feed }}} \\
(\mathrm{mM})\end{array}$} & \multicolumn{3}{|c|}{$\operatorname{AMPS}_{\mathrm{co}}(11)$} & \multicolumn{2}{|c|}{$\mathrm{AMPS}_{\mathrm{co}}(20)$} & \multicolumn{2}{|c|}{$\operatorname{AMPS}_{\mathrm{co}}(30)$} \\
\hline & No additives & Salt & СТАВ & No additives & Salt & No additives & Salt \\
\hline 10 & 39 & 55 & 67 & 39 & 44 & 54 & 54 \\
\hline 20 & 30 & 41 & 28 & 19 & 31 & 46 & 56 \\
\hline 40 & 30 & 36 & 31 & 16 & 33 & 36 & 54 \\
\hline 50 & 28 & 35 & 56 & 21 & 32 & 36 & 54 \\
\hline 60 & 30 & 34 & 49 & 20 & 33 & 36 & 47 \\
\hline 70 & 31 & 31 & 59 & 20 & 33 & 34 & 34 \\
\hline
\end{tabular}

$[\mathrm{NaCl}]=1 M$ and $\left.[\mathrm{CTAB}]=0.04 \mathrm{~g} / \mathrm{L} . \operatorname{AMPS}_{\mathrm{co}}(11)\right]=1.5 \mathrm{~g} / \mathrm{L} ;\left[\operatorname{AMPS}_{\mathrm{co}}(20)\right]=0.6$ $\mathrm{g} / \mathrm{L}$, and $\left[\mathrm{AMPS}_{\mathrm{co}}(30)\right]=0.6 \mathrm{~g} / \mathrm{L}$. 
cally. This behavior may be due to various interactions between the copolymers and regenerated cellulose resulting in the adsorption of surfactant onto membrane surface and pores. The hydrophobic interactions are mainly determined by hydrophobic properties of membrane materials and by the hydrophilichydrophobic balance of the surfactant. Interactions forces increase with an increase of the hydrophobic groups, as shown by $\operatorname{AMPS}_{\mathrm{co}}(30)$.

Addition of CTAB to aqueous solution of $\mathrm{AMPS}_{\mathrm{co}}$ copolymer results in the formation of aggregates at a surfactant concentration much lower than the CAC for pure $\mathrm{CTAB}$. This early mixed aggregation process promoted by the polyelectrolyte leads to higher rejection ratios.

The rejection ratios obtained under different environmental conditions seems promising for the application of these hydrophobically modified polyelectrolytes based on AMPS, as an increase of rejection with operating pressure is usually observed in ultrafiltration mainly due to the water flux increase. ${ }^{28}$

In summary, the fluorescence, viscosimetric, and binding experiments give unambiguous evidence for the aggregation and formation of hydrophobic microdomains, in water solutions of the copolymers that are able to solubilize preferentially hydrophobic compounds, such as the used fluorescent probe, NBD-derivative. Overall, equilibrium dialysis indicates that $\mathrm{AMPS}_{\mathrm{co}}$ aggregates are capable of interacting with and capturing metal ions such as $\mathrm{Cu}^{2+}$ as well as organic pollutants such as $m$-cresol.

\section{CONCLUSIONS}

A series of novel copolymers were prepared by means of copolymerization of AMPS and iDMA. Fluorescence and viscosimetry methods were used to study the association behavior of the copolymers in water solution. The results show that the copolymers are amphiphilic in nature and self-assembly to form aggregates in water, and this trend strengthened with the increase of hydrophobic content in the copolymer.

The CAC, fluorimetrically determined, was between 1.2 and $0.04 \mathrm{~g} / \mathrm{L}$ depending on the hydrophobe content in the copolymer. Hydrophobically modified copolymers associate strongly with cationic surfactants and form mixed aggregates which contain surfactant molecules (CTAB) and alkyl side groups of the polymer. The polymer/surfactant association starts at surfactant concentrations well below the CAC observed in the absence of CTAB.

The studied $\mathrm{AMPS}_{\mathrm{co}}$ copolymers compare well with small molecules surfactants as potential remediative agents for wastewater. Although the low- molecular-weight surfactants have been shown to have rejection ratios higher than $95 \%$, these systems show several disadvantages compared to polymeric surfactants, such as the loss of surfactant across the filtration membrane or limited permeate flux. Although the rejection ratios for some of the systems are low, multiple passes through ultrafiltration devices may be utilized to achieve high removal of water foulants.

\section{References}

1. Schmidt, M., Ed. Polyelectrolytes with Defined Molecular Architecture; Springer: Heidelberg, 2004.

2. Kujawa, P.; Rosiak, J. M.; Selb, J.; Candau, F. Macromol Chem Phys 2001, 202, 1384.

3. Yamamoto, H.; Morishima, Y. Macromolecules 1999, 32, 7469.

4. Mizusaki, M.; Morishima, Y.; Winnik. F. Macromolecules 1999, 32,4317

5. Alonso, A.; Catalina, F.; Salvador, E. F.; Peinado, C. Macromol Chem Phys 2001, 202, 2293.

6. Noda, T.; Hashidzume, A.; Morishima, Y. Polymer 2001, 42, 9243.

7. Sumerlin, B. S.; Lowe, A. B.; Thomas, D. B.; McCormick, C. L. Macromolecules 2003, 36, 5982.

8. Glas, J. E., Ed. Associating Polymers in Aqueous Solution (ACS Symposium Series, Vol. 765); American Chemical Society: Washington, DC, 2000.

9. McCormick, C. L. Stimuli Responsive Water Soluble and Amphiphilic Polymers (ACS Symposium Series, Vol. 780); American Chemical Society: Washington, DC, 2001.

10. Olea, A. F.; Gamboa, C. J Colloid Interface Sci 2003, 268, 63.

11. Stalikas, C. D. Trends Anal Chem 2002, 21, 343.

12. Turner, M. S.; Joanny, J. F. J Phys Chem 1993, 97, 4825.

13. Baskar, G.; Chandrasekar, K.; Reddy, B. S. R. Polymer 2004, $45,6507$.

14. Noda, T.; Morishima, Y. Macromolecules 1999, 32, 4631.

15. Fery-Forgues, S.; Fayet, J. P.; Lopez, A. J Photochem Photobiol A Chem 1993, 70, 229.

16. Reiller, P.; Lemordant, D.; Hafiane, A.; Moulin, C.; Beucaire, C. J Colloid Interface Sci 1996, 177, 519.

17. Juang, R. S.; Su, Y.-Y.; Chen, C.-L. J Membr Sci 2003, 218, 257.

18. Hebrant, M.; Provin, C.; Brunette, J.-P.; Tondre, C. Colloids Surf A 2001, 181, 225.

19. Akita, S.; Castillo, L. P.; Nii, S.; Takahashi, K.; Takeuchi, H. J Membr Sci 1999, 162, 111.

20. Dharmawardana, U. R.; Christian, S. D.; Taylor, R. W.; Scamehorn, J. F. Langmuir 1992, 8, 414.

21. Blagodatskikh, I. V.; Vasil'eva, O. V.; Ivanova, E. M.; Bykov, S. V.; Churochkina, N. A.; Pryakhina, T. A.; Smirnov, V. A.; Philippova, O. E.; Khokhlov, A. R. Polymer 2004, 45, 5897.

22. Gilbert, R. G. Emulsion Polymerization. A Mechanistic Approach; Academic Press: New York, 1995.

23. Piculell, L.; Guillemet, F.; Thuresson, K.; Shubin, V.; Ericson, O. Adv Colloid Interface Sci 1996, 63, 1.

24. Senan, C.; Meadows, J.; Shone, P. T.; Williams, P. A. Langmuir 1994, 10, 2471.

25. Fedors, R. F. Polymer 1979, 20, 225.

26. Dobrynin, V. A.; Colby, R. H.; Rubinstein, M. Macromolecules 1995, 28, 1859.

27. Mahmoud, F. Z.; Higazo, W. F.; Christian, S. D.; Tucker, E. E.; Taha, A. A. J Colloid Interface Sci 1989, 131, 96.

28. Kim, C. K.; Kim, S. S.; Kim, D. W.; Lim, J. C.; Kim, J. J. J Membr Sci 1998, 147, 13. 